\title{
Health economic analysis of costs of laparoscopic and open surgery for rectal cancer within a randomized trial (COLOR II)
}

\author{
Jacob Gehrman $^{1} \cdot$ Ingela Björholt $^{2} \cdot$ Eva Angenete $^{1} \cdot$ John Andersson ${ }^{1} \cdot$ \\ Jaap Bonjer ${ }^{3} \cdot$ Eva Haglind ${ }^{1}$
}

Received: 28 January 2016/ Accepted: 6 July 2016/Published online: 15 July 2016

(c) The Author(s) 2016. This article is published with open access at Springerlink.com

\begin{abstract}
Background Previous studies regarding the comparative costs of laparoscopic and open surgery for rectal cancer provide ambiguous conclusions, and there are no large randomized trials or long-term follow-up.

Methods A prospective cost-minimization analysis was carried out by using data of clinical resource use from the randomized controlled trial COLOR II. Some data needed for the health economic evaluation were not collected in the clinical trial; therefore, a retrospective data collection was made for COLOR II-patients operated at the largest participating Swedish hospital $(n=105)$. Sick leave information was provided by the Swedish social insurance agency. Unit costs were collected from Swedish sources. The primary outcome was the difference in mean cost between laparoscopic and open surgery.

Results The COLOR II-trial enrolled 1044 rectal cancer patients randomized between laparoscopic and open surgery 2:1. At the 3-year follow-up data for the clinical variables used in the analysis were available for 74-89\% of patients. Laparoscopic surgery costs the health care sector more than the open technique, both at 28 days $(\$ 1910,95 \% \mathrm{CI} 677-3143)$ and 3 years $(\$ 3854,95 \% \mathrm{CI}$
\end{abstract}

Jacob Gehrman

jacob.gehrman@gu.se

1 Department of Surgery, Institute of Clinical Sciences, Sahlgrenska Academy, University of Gothenburg, SSORG-Scandinavian Surgical Outcomes Research Group, Sahlgrenska University Hospital/Östra, SE-416 85 Gothenburg, Sweden

2 Nordic Health Economics, Gothenburg, Sweden

3 Department of Surgery, VUmc University Medical Centre, Amsterdam, The Netherlands
1527-6182) after surgery. There were, however, no differences in long-term costs to society between laparoscopic and open surgery ( $\$ 684,95 \% \mathrm{CI}-5799$ to 7166 ).

Conclusions Though the study found short- and long-term cost differences for the healthcare sector, there was no difference in regard to the long-term societal perspective. Future research is suggested to investigate the effects of sick leave costs using material from a greater number of patients.

Keywords Health economics - Cost-minimization analysis $\cdot$ Costs $\cdot$ Rectal cancer surgery

\section{Background}

Several smaller series and one large randomized trial, the COLOR (COlorectal cancer Laparoscopic or Open Resection) II-trial [1], have shown that laparoscopic surgery for rectal cancer has short-term benefits and is safe in comparison to open surgery. The short-term outcomes of the COLOR II-trial found that the laparoscopic group had less blood loss and a shorter hospital stay, but longer operating room time [2]. The analysis of the primary endpoint showed no difference with regard to loco-regional recurrence rates. There was no statistically significant difference in 3-year survival between the surgical procedures [3]. The study continues to monitor the disease-free and overall survival rates 5 years after surgery. The short-term outcomes of the ACOSOG Z6051 [4] and ALaCaRT [5] randomized clinical trials of laparoscopic and open rectal cancer resections failed to establish non-inferiority in terms of the pathological and adequate surgical resection outcomes. These trials have, however, used other endpoints, both are short-term and the group sizes are such that 
clinically relevant long-term oncological results cannot be ascertained.

Uncertainties remain regarding the relative costs of laparoscopic and open rectal cancer surgery. Several studies performed alongside randomized trials comparing the costs of laparoscopic and open surgery for rectal cancer have had short time perspectives [6-9] or have not included the cost of sick leave [8-10]; the results are difficult to interpret from a societal viewpoint.

The aim of the present study was to evaluate the cost of laparoscopic versus open resection for rectal cancer from both the healthcare and the societal perspective, based on the randomized COLOR II-trial. The health economic method employed was a cost-minimization analysis (see health economic methodology). The costs were assessed at 28 days (short-term analysis) and 3 years (long-term analysis). The hypothesis was that laparoscopic surgery would be more costly when assessed at 28 days after the primary operation but not at 3 years.

\section{Materials and methods}

\section{The COLOR II-trial}

The COLOR II-trial provided the clinical data for the present cost study [11]. The study was designed as a noninferiority trial undertaken at thirty hospitals in eight countries (Belgium, Canada, Denmark, Germany, the Netherlands, Spain, Sweden and South Korea) between January 2004 and May 2010 [11]. The patients were randomized on a 2:1 basis, 699 patients in the laparoscopic resection group and 345 in the open resection group. The trial was stratified by center, location of tumor and radiotherapy prior to surgery $[2,11]$. During the course of the trial, clinical record forms (CRF) were administered, one each for the pre-, intra- and postoperative stages (up to 28 days after the operation) and one CRF per year up to 5 years after the index surgery. In case of complications, reoperations or recurrences an additional CRF was completed. At the primary endpoint data were available for 771 patients $(74 \%)$ regarding loco-regional recurrence and for 903 patients $(87 \%)$ concerning overall survival [3]. The institutional review board at each participating center approved the trial. All patients provided informed consent in writing.

\section{Health economic methodology}

Health economic evaluations such as cost-effectiveness analysis are based on the incremental cost for an incremental unit of a clinically relevant outcome (mortality or morbidity) or a QALY (quality-adjusted life-years) as a measure of treatment or program effectiveness [12]. Survival and health-related quality of life [13, 14] were not statistically different in COLOR II (N.B. non-inferiority trial), and consequently a cost-minimization rather than a cost-effectiveness analysis was appropriate for the analysis [15]. This method implies a comparison of the costs for treatment alternatives that achieve a common outcome to an equal degree [12]. The rationale for the included cost components in the present study is outlined in more detail in Björholt et al. [16]

The cost analysis comprises the health care and the societal perspective, where the latter adds the cost of sick leave to the direct healthcare cost. The study period was set from inclusion into the clinical trial up to 3 years postoperatively, including the short- and long-term clinical endpoints of the COLOR II-study. Censoring and missing data can cause bias in economic studies conducted alongside clinical trials [17]. In this trial, the return rate of clinical record forms was high and it was assumed from a clinical perspective that censored patients and patients with missing data would not differ from non-censored patients and patients with complete data in the aspects affecting cost. One-way sensitivity analysis was employed to challenge the impact of variables sensitive to censoring mechanisms and missing data, i.e., reoperation, stoma care and sick leave. The analysis shows how the difference in mean cost between the surgical techniques is affected by changes $( \pm 30 \%)$ in cost per variable for each procedure.

\section{Data collection}

\section{Resource use}

Data on resource use were collected prospectively through CRF's in the COLOR II-trial. Details of the use of resources that were needed for this study, but had not been collected within the trial (basic laparoscopic equipment, surgical instruments, anesthesia time and time in recovery room), were determined using other sources.

The basic equipment required for laparoscopic surgery, as well as the type and quantity of instruments required for laparoscopic and open surgery, was determined by conclusions drawn from the health economic evaluation of laparoscopic versus open colon cancer resection within the framework of the randomized trial COLOR [18] and in collaboration with senior surgeons. Data regarding duration of anesthesia and time in the recovery room were collected from the records of COLOR II-patients operated on at the Sahlgrenska University Hospital in Sweden $(n=105)$. The factor between time in anesthesia and skin-to-skin time was established for the Sahlgrenska patients and applied on all COLOR II-patients. The average time in the recovery room for COLOR II-patients operated on at Sahlgrenska 
University Hospital was extrapolated to all study participants.

Sick leave was retrieved from the Swedish Social Insurance Agency for Swedish COLOR II-patients, and the observed average number of days on sick leave per surgical technique was calculated. To be able to analyze the total cost at the patient level, the average number of sick leave days per surgical technique observed in the Swedish cohort was applied to the non-Swedish COLOR II-population using random selection. It was ascertained that the proportion of patients on sick leave in the Swedish cohort, and the non-Swedish COLOR II-populations was the same.

\section{Unit costs}

Unit costs for basic equipment and surgical instruments were obtained from regional procurement records in Region Västra Götaland, Sweden. The cost per minute in the operating room, time in anesthesia and time in the recovery room were derived from the health economic evaluation of laparoscopic versus open surgery in the COLOR trial [18]. The unit costs for consumables related to stoma care were obtained from pharmacy retail prices in Sweden. The Swedish cost per patient database contains cost data for approximately $70 \%$ of inpatient care in Sweden. The unit cost per type of reoperation in this study was estimated by taking the average cost for the matching procedure in the cost per patient database. Therefore, the cost per reoperation was based on a larger sample which reduced the potential variability in resource use of these rare and costly events. It was assumed that the type of reoperation was unrelated to the original surgical technique, as no significant differences in complications or reoperations were found in the COLOR II-study [2].

The cost of sick leave was calculated by using the average monthly wage (provided by Statistics Sweden) with addition of the social security and supplementary pension fees. All prices were inflation adjusted for 2013 SEK using the consumer price index provided by Statistics Sweden. Costs were converted from SEK to the average value of the US dollar in $2013(\$ 1=6.51$ SEK).

\section{Statistical methods}

The distribution of cost data is non-negative and right skewed due to the low number of patients incurring particularly high costs, a common phenomenon in studies involving resource items with high unit costs such as hospital care, reoperations and sick leave. The average cost will consequently be higher than the cost of the average patient, but it is still meaningful as it enables the calculation of the total cost of treating all patients with the new therapy [17]. Due, however, to the central limit theorem statistical inference based on the normality assumption regarding average cost is valid despite the skewed distribution. A non-parametric bootstrap was included as a robustness check of the results [19].

\section{Results}

For the health economic study, 699 patients in the laparoscopic group and 345 in the open group were available for analysis (Fig. 1). Information relevant for the short-term outcomes of the study was available for between 98 and $100 \%$ of the patients. Concerning the long-term analysis data were available for 74-89\% of the patients. The baseline clinical characteristics (Table 1) were not significantly different between laparoscopic and open resection. The resource use and the corresponding unit costs associated with each treatment are shown in Tables 2 and 3 , respectively. Table 4 displays the mean cost per resource use category and treatment, and Table 5 shows the difference in means and the main outcome of the study. The bootstrap method did not affect the $p$ value for any of the results in Table 5, but the confidence intervals became narrower.

\section{Healthcare perspective}

The mean healthcare cost per patient (Table 5) during the 28 days following surgery was significantly higher in the laparoscopic group \$16226 (SEK, 105694) than in the open group \$14316 (SEK, 93253), yielding a difference of $\$ 1910$ (SEK, 12440) (CI95 \% 677-3143). Three years after surgery, this difference had increased to \$3854 (SEK 25107) (CI95 \% 1527-6182).

\section{Societal perspective}

From the societal perspective, the mean cost per patient (Table 5) at 28 days following surgery was significantly higher in the laparoscopic group $\$ 18113$ (SEK, 117990) than in the open group $\$ 16261$ (SEK 105926), with a difference of $\$ 1852$ (SEK, 12063) (95\% CI 533-3171). Three years after surgery, the difference was not significant and had decreased to $\$ 684$ (SEK, 4453) (95\% CI -5799 to 7166 ).

\section{Sensitivity analyses}

Sensitivity analyses can be found in Table 6. From the short-term healthcare and societal perspectives length of hospital stay were the only variable demonstrating significant sensitivity (difference in mean cost became negative) to the variation of the base case value. Long-term societal costs were affected by the number of days on sick leave. 
Fig. 1 Study flow chart and COLOR II

Table 1 Baseline clinical characteristics and pathology

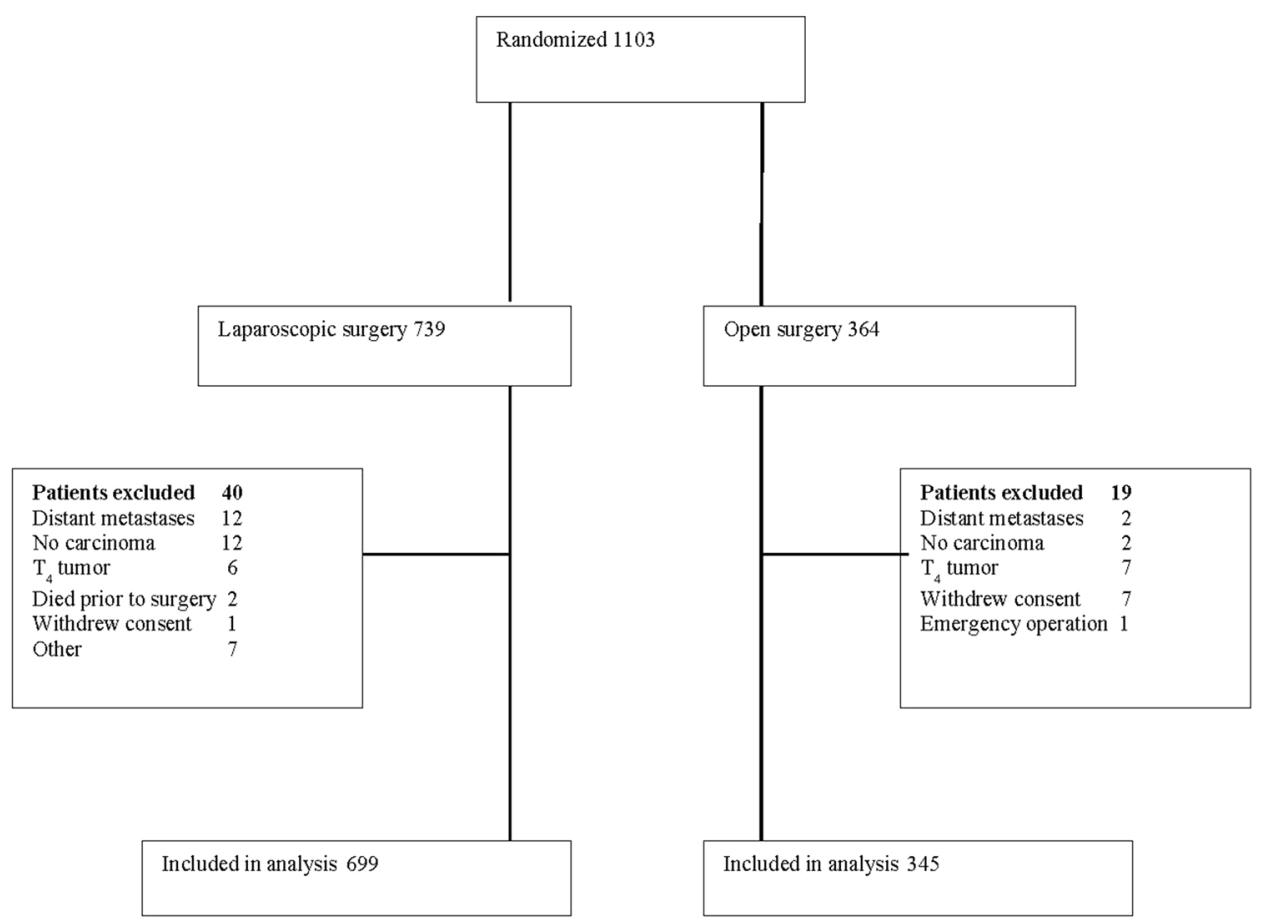

\begin{tabular}{lll}
\hline Characteristics & Laparoscopic surgery $(n=699)$ & Open surgery $(n=345)$ \\
\hline Gender, no. (\%) & & \\
Male & $448 / 699(64)$ & $211 / 345(61)$ \\
Female & $251 / 699(36)$ & $134 / 345(39)$ \\
Age, mean (SD), years & $66.8(10.5)$ & $65.8(10.9)$ \\
American Society of Anesthesiologists classification, no. $(\%)$ & \\
I & $156 / 678(23)$ & $65 / 338(19)$ \\
II & $386 / 678(57)$ & $211 / 338(62)$ \\
III & $131 / 678(19)$ & $61 / 338(18)$ \\
IV & $5 / 678(<1)$ & $1 / 338(<1)$ \\
Missing data & $21 / 699(3)$ & $7 / 345(2)$ \\
Body-mass index, mean (SD), kg/m ${ }^{2}$ & $26.1(4.5)$ & $26.5(4.7)$ \\
Location of tumor (distance from anal verge), no. $(\%)$ & $116 / 345(34)$ \\
Upper rectum $(10-15 \mathrm{~cm})$ & $223 / 699(32 \%)$ & $136 / 345(39)$ \\
Middle rectum $(5-10 \mathrm{~cm})$ & $273 / 699(39 \%)$ & $93 / 345(27)$ \\
Lower rectum $(<5 \mathrm{~cm})$ & $203 / 699(29 \%)$ & \\
Clinical stage, no. $(\%)$ & & $96 / 329(29)$ \\
I & $201 / 667(30)$ & $107 / 329(33)$ \\
II & $209 / 667(31)$ & $126 / 329(38)$ \\
III & $257 / 667(38)$ & $16 / 345(5)$ \\
Missing data & $32 / 699(5)$ &
\end{tabular}

\section{Additional sensitivity analysis}

The incidence of colostomy had considerable impact on the study result and so did the number of days on sick leave. A detailed analysis of the data showed that patients in the open surgery group were older, and therefore, fewer were eligible for sick leave compared with patients in the laparoscopic group. Numerically more patients on sick leave in the laparoscopic group died earlier compared to the open group which resulted in a lower cost of sick leave in the laparoscopic group. As survival did not significantly differ between the groups, this was most likely a random 
Table 2 Clinical resource use

\begin{tabular}{|c|c|c|c|}
\hline Type of resource & $\begin{array}{l}\text { Laparoscopic surgery } \\
(n=699)\end{array}$ & $\begin{array}{l}\text { Open surgery } \\
(n=345)\end{array}$ & Source \\
\hline Basic laparoscopic equipment, no (\%) & $699(100)$ & $0(0)$ & COLOR II \\
\hline Surgical instruments, no $(\%)^{\mathrm{a}}$ & & & COLOR II \\
\hline TME & $396 / 699(57)$ & $219 / 345(63)$ & \\
\hline Other (APR, PME) & $294 / 699(42)$ & $126 / 345(37)$ & \\
\hline Missing & $9 / 699(1)$ & $0 / 345(0)$ & \\
\hline Skin-to-skin time, $\min$ & $247(83)$ & $200(69)$ & COLOR II \\
\hline Time in anesthesia, $\min ^{\mathrm{b}}$ & $306(104)$ & $256(89)$ & Subset of COLOR II-patients \\
\hline Time in recovery room, $\min ^{b, c}$ & $992(\mathrm{~N} / \mathrm{A})$ & 1054 (N/A) & Subset of COLOR II- patients \\
\hline Length of hospital stay $<28$ days, days & $11.5(6.5)$ & $12.1(6.0)$ & COLOR II \\
\hline Length of hospital stay $<3$ years, days & $12.8(11.5)$ & $13.4(11.0)$ & COLOR II \\
\hline Days with ileostomy $<28$ days, days & $10.5(13.5)$ & $10.8(13.6)$ & COLOR II \\
\hline Days with ileostomy $<3$ years, days & $91(182)$ & $80(139)$ & COLOR II \\
\hline Days with colostomy $<28$ days, days & $9.7(13.2)$ & $8.1(12.6)$ & COLOR II \\
\hline Days with colostomy $<3$ years, days & $363(502)$ & $281(461)$ & COLOR II \\
\hline No. $(\%)$ of patients with reoperation $<28$ days & & & COLOR II \\
\hline No & $588 / 697(84)$ & $299 / 345(87)$ & \\
\hline Yes & 109/697 (16) & $46 / 345(13)$ & \\
\hline No. $(\%)$ of patients with reoperation $<3$ years & & & COLOR II \\
\hline No & $459 / 697(66)$ & $240 / 345(70)$ & \\
\hline Yes & 238/697 (34) & $105 / 345(30)$ & \\
\hline Reasons for reoperation $(<3 \text { years })^{\mathrm{d}}$ & & & COLOR II \\
\hline Recurrence & 28 & 14 & \\
\hline Complication & 217 & 89 & \\
\hline Stoma reversal & 68 & 28 & \\
\hline Complication and new stoma & 48 & 21 & \\
\hline Not related to rectal surgery & 10 & 7 & \\
\hline Sick leave $<28$ days, days ${ }^{\mathrm{e}}$ & $6.2(11.6)$ & $6.4(11.8)$ & $\begin{array}{l}\text { Swedish Social Insurance } \\
\text { Agency }\end{array}$ \\
\hline Sick leave $<3$ years, days ${ }^{\mathrm{e}}$ & 75 (137) & $86(157)$ & $\begin{array}{l}\text { Swedish Social Insurance } \\
\text { Agency }\end{array}$ \\
\hline
\end{tabular}

Values are mean (standard deviation) unless stated otherwise

a TME-Resection with total mesorectal excision, APR-Abdominoperineal resection, PME-Resection with partial mesorectal excision. Described in more detail in van der Pas et al. [2]. A set of surgical instruments used for open and laparoscopic TME and non-TME was determined in collaboration with senior surgeons. The number of TME and non-TME was collected from the COLOR II-trial

b Collected within the Swedish cohort of COLOR II operated at the Sahlgrenska University Hospital, Gothenburg

c The mean value of time in recovery room in the Swedish cohort and in the global study population all patients were assigned these mean values, i.e., std. dev. not possible to calculate

${ }^{\mathrm{d}}$ Long-term data $(<3$ years) from RCT COLOR II previously not published. Several patients have had more than one reoperation collected within the Swedish cohort of COLOR II only

${ }^{\mathrm{e}}$ Collected within the Swedish cohort of COLOR II only

finding due to sick leave only having been examined in a small sub-group of the COLOR II-trial. The mean number of days with a colostomy was higher in the laparoscopic group, partly due to numerically more laparoscopic patients subject to abdominoperineal resection at the index operation and partly due to longer survival time in the sub-group of colostomy patients in the laparoscopic group. Additional sensitivity analyses were, therefore, performed and the results showed that excluding the costs of stoma material the difference in mean cost per patient to the health care sector (\$1886, $95 \%$ CI 657-3115) (SEK, 12286) was similar to the base case analysis at 28 days after the index 
Table 3 Unit costs

\begin{tabular}{llll}
\hline Resource use category & Unit cost (USD) & Unit & Source \\
\hline $\begin{array}{l}\text { Basic laparoscopic equipment } \\
\text { Surgical instruments }\end{array}$ & 281 & Per laparoscopic resection & Region Västra Götaland, Sweden \\
Open TME & 931 & & Region Västra Götaland, Sweden \\
Laparoscopic TME & 2101 & Per open TME & \\
Open non-TME & 784 & Per laparoscopic TME & \\
Laparoscopic non-TME & 1779 & Per open non-TME & \\
Skin-to-skin time & 11 & Per laparoscopic non-TME & \\
Duration of anesthesia & 5 & Per minute & Janson et al. 2004 \\
Time in recovery room & 1 & Per minute & Janson et al. 2004 \\
Length of hospital stay & 531 & Per minute & Janson et al. 2004 \\
Ileostomy & 12 & Per day & Janson et al. 2004 \\
Colostomy & 18 & Per day & Pharmacy sales price \\
Reoperation & N/A & Per day & Pharmacy sales price \\
Sick leave & 303 & Per type of reoperation & Swedish association of local authorities and regions \\
\hline
\end{tabular}

a TME-Resection with total mesorectal excision, APR-Abdominoperineal resection and PME-Resection with partial mesorectal excision. Described in more detail in van der Pas et al. [2]

b The type of reoperation was collected within the COLOR II-trial. The unit cost per type of reoperation was collected from a national database (Swedish association of local authorities and regions) containing the costs for approximately $70 \%$ of the Swedish in-patient episodes of care

Table 4 Mean cost and difference in mean cost per resource use category

\begin{tabular}{|c|c|c|c|}
\hline Resource use category & $\begin{array}{l}\text { Mean cost per patient/laparoscopic surgery } \\
\text { (USD) }\end{array}$ & $\begin{array}{l}\text { Mean cost per patient/open surgery } \\
\text { (USD) }\end{array}$ & $\begin{array}{l}\text { Difference in mean costs } \\
\text { (USD) }\end{array}$ \\
\hline $\begin{array}{l}\text { Basic laparoscopic } \\
\text { equipment }\end{array}$ & $281(0)$ & N/A & 281 (N/A) \\
\hline Surgical instruments & 1964 (159) & $878(71)$ & $1087(7)$ \\
\hline Skin-to-skin time & $2676(898)$ & $2161(750)$ & $514(53)$ \\
\hline Duration of anesthesia & $1545(526)$ & $1293(451)$ & $252(32)$ \\
\hline Time in recovery room & 1074 (N/A) & 1141 (N/A) & $-67(\mathrm{~N} / \mathrm{A})$ \\
\hline \multicolumn{4}{|l|}{ Length of hospital stay } \\
\hline 28 days & $6129(3427)$ & $6431(3210)$ & $-302(221)$ \\
\hline 3 years & $6796(6129)$ & $7117(5844)$ & $-321(398)$ \\
\hline \multicolumn{4}{|l|}{ Stoma } \\
\hline Ileostomy 28 days & $124(158)$ & $127(160)$ & $-3,6(10)$ \\
\hline Ileostomy 3 years & $1070(2142)$ & $941(1630)$ & $129(120)$ \\
\hline Colostomy 28 days & $174(238)$ & $146(227)$ & $27(15)$ \\
\hline Colostomy 3 years & $6519(9022)$ & $5038(8288)$ & $1481(578)$ \\
\hline \multicolumn{4}{|l|}{ Reoperation } \\
\hline 28 days & $2397(7280)$ & $2199(7591)$ & $198(486)$ \\
\hline 3 years & $5902(11,867)$ & $5323(11,580)$ & $578(775)$ \\
\hline \multicolumn{4}{|l|}{ Sick leave } \\
\hline 28 days & $1888(3447)$ & $1945(3575)$ & $-58(230)$ \\
\hline 3 years & $22,793(41,618)$ & $25,964(47,712)$ & $-3171(3014)$ \\
\hline
\end{tabular}

Values are mean (standard deviation), except difference in mean costs (standard error) 
Table 5 Mean total cost and difference in mean total cost per surgical technique

\begin{tabular}{|c|c|c|c|c|}
\hline $\begin{array}{l}\text { Perspective and time of } \\
\text { analysis }\end{array}$ & $\begin{array}{l}\text { Mean total cost laparoscopic } \\
\text { resection (USD) }\end{array}$ & $\begin{array}{l}\text { Mean total cost open resection } \\
\text { (USD) }\end{array}$ & $\begin{array}{l}\text { Difference in mean total cost } \\
(95 \% \mathrm{CI})\end{array}$ & $p$ value \\
\hline \multicolumn{5}{|l|}{ Health care costs 28 days } \\
\hline Parametric & $16,226(10,140)$ & $14,316(10,361)$ & $1910(677$ to 3143$)$ & $<0.002$ \\
\hline $\begin{array}{l}\text { Nonparametric } \\
\text { (bootstrap) }\end{array}$ & & & $1910(685$ to 3123$)$ & $<0.003$ \\
\hline \multicolumn{5}{|l|}{ Health care costs 3 years } \\
\hline Parametric & $27,686(46,198)$ & $23,831(51,993)$ & 3854 (1527 to 6182$)$ & $<0.001$ \\
\hline $\begin{array}{l}\text { Nonparametric } \\
\text { (bootstrap) }\end{array}$ & & & 3854 (1491 to 6053) & $<0.001$ \\
\hline \multicolumn{5}{|l|}{ Societal costs 28 days } \\
\hline Parametric & $18,113(9524)$ & $16,261(9591)$ & $1852(533$ to 3171$)$ & $<0.006$ \\
\hline $\begin{array}{l}\text { Nonparametric } \\
\text { (bootstrap) }\end{array}$ & & & 1852 (391 to 3110$)$ & $<0.006$ \\
\hline \multicolumn{5}{|l|}{ Societal costs 3 years } \\
\hline Parametric & $50,479(18,162)$ & $49,795(17,719)$ & $684(-5799$ to 7166$)$ & 0.84 \\
\hline $\begin{array}{l}\text { Nonparametric } \\
\text { (bootstrap) }\end{array}$ & & & $684(-5698$ to 7255$)$ & 0.84 \\
\hline
\end{tabular}

Values are mean (standard deviation) unless stated otherwise. Bootstrap confidence intervals and $p$ values are based on 2000 replications

surgery. At 3 years the difference in mean health care cost per patient (\$2245, $95 \%$ CI 270-4219) (SEK, 14621) was lower compared to the base case analysis (\$3854). Laparoscopic surgery was numerically less costly per patient for society than open surgery $-\$ 926$ (SEK, -6034) (95\% CI -7261 to 5409 ) at 3 years after primary operation. In the short time perspective, it made little difference (\$1828, $95 \%$ CI 513-3144) (SEK, 11909).

\section{Discussion}

This health economic evaluation of laparoscopic and open surgery for rectal cancer in the framework of the randomized trial COLOR II showed that laparoscopy was significantly more costly from the societal perspective at 28 days, but no statistical significance was detected at 3 years. From a healthcare perspective, laparoscopy was more costly than open surgery at both 28 days and 3 years.

The one-way sensitivity analyses showed that variations in sick leave and the incidence and days with colostomy had a large impact on the results. Data on sick leave were elicited for the Swedish sub-group only $(n=251)$, which increased the risk of random findings. This is a common problem for costly resource use items that may vary without relation to the studied interventions. In this study, the finding was a disadvantage to the results in the open surgery group. On the other hand, patients with a cancer in the lowest part of the rectum, who received a colostomy due to abdominoperineal resection, lived longer (n.s.) and were numerically more frequent in the laparoscopic group [3]. Since colostomies are costly and a longer follow-up time involves further costs, this was a disadvantage for the laparoscopic group. The additional sensitivity analyses confirmed that when stoma costs were deducted from the health care costs, the difference in mean cost per patient was reduced. For the long-term societal costs, the difference (laparoscopic minus open surgery) in mean cost per patient changed from $\$ 684$ (base case) to $-\$ 926$ (n.s.).

There are few findings about the cost of rectal cancer surgery and they are divergent. Franks et al. [6] reported on a randomized trial including the initial 3 months after index surgery and found no significant difference in societal costs between open and laparoscopic surgery, but the time chosen for their analysis differs from that of our analysis and the number of patients were fewer in their study. Son et al. [8] found statistically significant higher median costs for laparoscopic rectal resection compared to open, utilizing data for a cohort of a randomized trial. Using median costs makes it difficult to compare it to the results of the present study, since our results present mean costs. Their health economic evaluation covered the first three postoperative months and healthcare costs only, whereas our analysis covers 3 years and includes societal costs.

The results from the societal perspective in this trial correspond to those from the earlier trial of laparoscopic versus open surgery for colon cancer (COLOR) [18], 
Table 6 Sensitivity analyses

\begin{tabular}{|c|c|c|c|c|c|}
\hline Perspective and time of analysis & Variable & Change in cost & Difference in mean (USD) & $95 \% \mathrm{CI}$ & \\
\hline \multicolumn{6}{|l|}{ Health care costs 28 days } \\
\hline & Base case cost & N/A & 1910 & 677 & 3143 \\
\hline & Skin-to-skin time & Lap $-30 \%$ & 1103 & -125 & 2330 \\
\hline & & Lap $+30 \%$ & 2671 & 1430 & 3912 \\
\hline & & Open $-30 \%$ & 2524 & 1293 & 3755 \\
\hline & & Open $+30 \%$ & 1250 & 13 & 2487 \\
\hline & Length of hospital stay & Lap $-30 \%$ & 79 & -1097 & 1255 \\
\hline & & Lap $+30 \%$ & 3740 & 2444 & 5037 \\
\hline & & Open $-30 \%$ & 3839 & 2632 & 5046 \\
\hline & & Open $+30 \%$ & -19 & -1282 & 1243 \\
\hline & Colostomy & Lap $-30 \%$ & 5970 & 2671 & 9269 \\
\hline & & Lap $+30 \%$ & 1700 & -1708 & 5108 \\
\hline & & Open $-30 \%$ & 1853 & -641 & 4348 \\
\hline & & Open $+30 \%$ & 1927 & -568 & 4422 \\
\hline & Reoperation & Lap $-30 \%$ & 1191 & 31 & 2350 \\
\hline & & Lap $+30 \%$ & 2629 & 1299 & 3958 \\
\hline & & Open $-30 \%$ & 2570 & 1505 & 3634 \\
\hline & & Open $+30 \%$ & 1250 & -180 & 2679 \\
\hline \multicolumn{6}{|l|}{ Health care costs 3 years } \\
\hline & Base case cost & N/A & 3854 & 1527 & 6182 \\
\hline & Length of hospital stay & Lap $-30 \%$ & 1824 & -413 & 4061 \\
\hline & & Lap $+30 \%$ & 5884 & 3455 & 8314 \\
\hline & & Open $-30 \%$ & 5989 & 3706 & 8272 \\
\hline & & Open $+30 \%$ & 1719 & -658 & 4097 \\
\hline & Reoperation & Lap $-30 \%$ & 2084 & -115 & 4283 \\
\hline & & Lap $+30 \%$ & 5625 & 3181 & 8068 \\
\hline & & Open $-30 \%$ & 5451 & 3365 & 7538 \\
\hline & & Open $+30 \%$ & 2257 & -308 & 4823 \\
\hline \multicolumn{6}{|l|}{ Societal costs 28 days } \\
\hline & Base case cost & N/A & 1852 & 533 & 3171 \\
\hline & Surgical instruments & Lap $-30 \%$ & 1269 & -50 & 2588 \\
\hline & & Lap $+30 \%$ & 2435 & 1115 & 3755 \\
\hline & & Open $-30 \%$ & 2115 & 796 & 3434 \\
\hline & & Open $+30 \%$ & 1589 & 269 & 2908 \\
\hline & Skin-to-skin time & Lap $-30 \%$ & 1124 & -102 & 2351 \\
\hline & & Lap $+30 \%$ & 2695 & 1455 & 3935 \\
\hline & & Open $-30 \%$ & 2547 & 1316 & 3777 \\
\hline & & Open $+30 \%$ & 1273 & 37 & 2509 \\
\hline & Length of hospital stay & Lap $-30 \%$ & 21 & -1244 & 1286 \\
\hline & & Lap $+30 \%$ & 3683 & 2302 & 5063 \\
\hline & & Open $-30 \%$ & 3781 & 2486 & 5076 \\
\hline & & Open $+30 \%$ & -77 & -1424 & 1270 \\
\hline & Reoperation & Lap $-30 \%$ & 1133 & -126 & 2391 \\
\hline & & Lap $+30 \%$ & 2571 & 1155 & 3987 \\
\hline & & Open $-30 \%$ & 2512 & 1344 & 3679 \\
\hline & & Open $+30 \%$ & 1192 & -321 & 2705 \\
\hline & Sick leave & Lap $-30 \%$ & 1286 & -7 & 2579 \\
\hline & & Lap $+30 \%$ & 2418 & 1064 & 3772 \\
\hline
\end{tabular}


Table 6 continued

\begin{tabular}{|c|c|c|c|c|c|}
\hline Perspective and time of analysis & Variable & Change in cost & Difference in mean (USD) & $95 \% \mathrm{CI}$ & \\
\hline & & Open $-30 \%$ & 2436 & 1132 & 3740 \\
\hline & & Open $+30 \%$ & 1268 & -71 & 2607 \\
\hline \multicolumn{6}{|l|}{ Societal costs 3 years } \\
\hline & Base case cost & N/A & 684 & -5799 & 7166 \\
\hline & Skin-to-skin time & Lap $-30 \%$ & 3069 & 749 & 5389 \\
\hline & & Lap $+30 \%$ & 4640 & 2305 & 6974 \\
\hline & & Open $-30 \%$ & 4491 & 2189 & 6794 \\
\hline & & Open $+30 \%$ & 3217 & 887 & 5548 \\
\hline & Sick leave & Lap $-30 \%$ & -6154 & $-12,241$ & -67 \\
\hline & & Lap $+30 \%$ & 7522 & 541 & 14,502 \\
\hline & & Open $-30 \%$ & 8473 & 3121 & 13,825 \\
\hline & & Open $+30 \%$ & -7106 & $-14,852$ & 641 \\
\hline
\end{tabular}

Lap Laparoscopic resection, open open resection

although the time frame was shorter in that study. Three previous studies have reported the cost of sick leave after colorectal cancer. In Franks et al. [6], the average cost of sick leave after rectal cancer surgery was higher in the laparoscopic than in the open resection group (the difference in average cost was $£ 10395 \%$ CI $£-576$ to $£ 368$ ). King et al. [7] reported the difference in average cost of productivity loss between laparoscopic and open resection of colorectal cancer within an enhanced recovery program to be $£ 274$ (bootstrap CI at 2.5 and $97.5 \%,-386$ to 983.2 ) less in the laparoscopic resection group. In a recent study by Crawshaw et al. [20], the difference in sick leave after colectomy was estimated to be on average 2.78 (95\% CI 1.93-3.59) days longer in the open resection group than in the laparoscopic resection group. That study was retrospective and based on national health insurance claims in USA. They evaluated health care utilization up to 1 year after primary operation and found the mean cost to be lower following laparoscopic surgery. Our study has a longer time perspective (3 years) and is based on a randomized controlled trial.

In the present study, the length of hospital stay was considerable in both groups, although 1 day shorter (median) in the laparoscopic group. The trial protocol prescribed that the same local principles for discharge should be applied for both groups and did not include the enhanced recovery after surgery (ERAS) concept [21]. The difference in hospital stay, however, between laparoscopic and open colorectal surgery is consistent with studies including enhanced recovery programs [22, 23]. The sensitivity analyses conducted in the present study indicated a potential for cost saving if length of hospital stay can be shortened. In one study, King et al. [7] evaluated the costs following laparoscopic and open surgery after colorectal cancer surgery within an enhanced recovery program and found a difference in mean cost of $£ 354$ (95\% CI -2 167 to 2 992) favoring laparoscopic surgery.

The strengths of our study include that it is based on clinical results from a large randomized trial with a multicenter design and that the principles for the health economic analysis were outlined before the start of the randomized trial. Thus, the clinical record forms included variables of importance for the economic analysis. The study also had a high rate of returned clinical record forms.

A limitation is that the present health economic analysis was a secondary objective within the randomized trial COLOR II and the sample size, thus, not calculated for the health economic outcomes. Further, some of the resource units are for a sub-group of patients of the COLOR II-trial, which adds to the uncertainty of these variables.

In conclusion, laparoscopic surgery for rectal cancer is more costly than open surgery from the health care perspective. It is important, however, that the cost of sick leave is taken into account to ensure inclusion of all costs arising as a consequence of the surgical method chosen. In the present study, sick leave was investigated in the Swedish cohort only which was too small to detect a true difference between the treatments. Future research is suggested to investigate the sick leave costs of rectal cancer surgery.

Acknowledgments The authors are thankful to RN. Sofia Erestam (Sahlgrenska University Hospital/Östra, Gothenburg, Sweden) for help regarding collection of data.

Funding/Support The study was supported by the Swedish Cancer Society (2013/497), Sahlgrenska University Hospital (ALF Grant 2014-4307771), Assar Gabrielsson Foundation, Alice Swenson Foundation, Gothenburg Medical Society, Anna-Lisa and Bror Björnsson Foundation and Axel Linders Foundation. 


\section{Compliance with ethical standards}

Disclosures Dr. Andersson reports grants from Assar Gabrielsson Foundation, Alice Swenson Foundation, Gothenburg Medical Society, Anna-Lisa and Bror Björnsson Foundation and Axel Linders Foundation, during the conduct of the study. Dr. Bonjer reports personal fees from Olympus, Stryker, Medtronic and Applied medical, outside the submitted work. Dr. Haglind reports grants from Swedish Cancer Society (2013/497) and Sahlgrenska University Hospital (ALF grant 2014-4307771) during the conduct of the study and grants from Swedish Research Council and Västra Götaland region outside the submitted work. Drs. Angenete, Björholt and Gehrman have no conflicts of interest or financial ties to disclose.

Open Access This article is distributed under the terms of the Creative Commons Attribution 4.0 International License (http://creative commons.org/licenses/by/4.0/), which permits unrestricted use, distribution, and reproduction in any medium, provided you give appropriate credit to the original author(s) and the source, provide a link to the Creative Commons license, and indicate if changes were made.

\section{References}

1. Vennix S, Pelzers L, Bouvy N, Beets GL, Pierie JP, Wiggers T, Breukink S (2014) Laparoscopic versus open total mesorectal excision for rectal cancer. Cochrane Database Syst Rev. doi:10. 1002/14651858.CD005200.pub3

2. van der Pas MH, Haglind E, Cuesta MA, Furst A, Lacy AM, Hop WC, Bonjer HJ, Group COcLoORIS (2013) Laparoscopic versus open surgery for rectal cancer (COLOR II): short-term outcomes of a randomised, phase 3 trial. Lancet Oncol 14:210-218

3. Bonjer HJ, Deijen CL, Abis GA, Cuesta MA, van der Pas MH, de Lange-de Klerk ES, Lacy AM, Bemelman WA, Andersson J, Angenete E, Rosenberg J, Fuerst A, Haglind E, Group CIS (2015) A randomized trial of laparoscopic versus open surgery for rectal cancer. N Engl J Med 372:1324-1332

4. Fleshman J, Branda M, Sargent DJ, Boller AM, George V, Abbas M, Peters WR Jr, Maun D, Chang G, Herline A, Fichera A, Mutch M, Wexner S, Whiteford M, Marks J, Birnbaum E, Margolin D, Larson D, Marcello P, Posner M, Read T, Monson J, Wren SM, Pisters PW, Nelson H (2015) Effect of laparoscopicassisted resection vs open resection of stage II or III rectal cancer on pathologic outcomes: the ACOSOG Z6051 randomized clinical trial. JAMA 314:1346-1355

5. Stevenson AR, Solomon MJ, Lumley JW, Hewett P, Clouston AD, Gebski VJ, Davies L, Wilson K, Hague W, Simes J (2015) Effect of laparoscopic-assisted resection vs open resection on pathological outcomes in rectal cancer: the ALaCaRT randomized clinical trial. JAMA 314:1356-1363

6. Franks PJ, Bosanquet N, Thorpe H, Brown JM, Copeland J, Smith AM, Quirke P, Guillou PJ (2006) Short-term costs of conventional vs laparoscopic assisted surgery in patients with colorectal cancer (MRC CLASICC trial). Br J Cancer 95:6-12

7. King PM, Blazeby JM, Ewings P, Franks PJ, Longman RJ, Kendrick AH, Kipling RM, Kennedy RH (2006) Randomized clinical trial comparing laparoscopic and open surgery for colorectal cancer within an enhanced recovery programme. Br J Surg 93:300-308

8. Son HJ, Lee HY, Park JW, Choi HS, Jeong SY, Oh JH (2013) Cost-comparison of laparoscopic and open surgery for mid or low rectal cancer after preoperative chemoradiotherapy: data from a randomized controlled trial. World J Surg 37:214-219

9. Leung KL, Kwok SPY, Lam SCW, Lee JFY, Yiu RYC, Ng SSM, Lai PBS, Lau WY (2004) Laparoscopic resection of rectosigmoid carcinoma: Prospective randomised trial. Lancet 363:1187-1192
10. Braga M, Frasson M, Vignali A, Zuliani W, Capretti G, Di Carlo V (2007) Laparoscopic resection in rectal cancer patients: outcome and cost-benefit analysis. Dis Colon Rectum 50:464-471

11. Color IISG, Buunen M, Bonjer HJ, Hop WC, Haglind E, Kurlberg G, Rosenberg J, Lacy AM, Cuesta MA, D'Hoore A, Furst A, Lange JF, Jess P, Bulut O, Poornoroozy P, Jensen KJ, Christensen MM, Lundhus E, Ovesen H, Birch D, Iesalnieks I, Jager C, Kreis M, van Riet Y, van der Harst E, Gerhards MF, Bemelman WA, Hansson BM, Neijenhuis PA, Prins HA, Balague C, Targarona E, Lujan Mompean JA, Franco Osorio JD, Garcia Molina FJ, Skullman S, Lackberg Z, Kressner U, Matthiessen P, Kim SH, Poza AA (2009) COLOR II. A randomized clinical trial comparing laparoscopic and open surgery for rectal cancer. Dan Med Bull 56:89-91

12. Drummond MF, Sculpher MJ, Torrance GW, O'Brien BJ, Stoddart GL (2005) Methods for the economic evaluation of health care programmes, 3rd edn. Oxford University Press, Oxford

13. Andersson J, Abis G, Gellerstedt M, Angenete E, Angeras U, Cuesta MA, Jess P, Rosenberg J, Bonjer HJ, Haglind E (2014) Patient-reported genitourinary dysfunction after laparoscopic and open rectal cancer surgery in a randomized trial (COLOR II). Br J Surg 101:1272-1279

14. Andersson J, Angenete E, Gellerstedt M, Angeras U, Jess P, Rosenberg J, Furst A, Bonjer J, Haglind E (2013) Health-related quality of life after laparoscopic and open surgery for rectal cancer in a randomized trial. Br J Surg 100:941-949

15. Briggs AH, O'Brien BJ (2001) The death of cost-minimization analysis? Health Econ 10:179-184

16. Bjorholt I, Janson M, Jonsson B, Haglind E (2006) Principles for the design of the economic evaluation of COLOR II: An international clinical trial in surgery comparing laparoscopic and open surgery in rectal cancer. Int $\mathbf{J}$ Technol Assess Health Care 22:130-135

17. Glick H, Doshi JA, Sonnad SS, Polsky D (2014) Economic evaluation in clinical trials, 2nd edn. Oxford University Press, Oxford

18. Janson M, Bjorholt I, Carlsson P, Haglind E, Henriksson M, Lindholm E, Anderberg B (2004) Randomized clinical trial of the costs of open and laparoscopic surgery for colonic cancer. Br J Surg 91:409-417

19. Barber JA, Thompson SG (2000) Analysis of cost data in randomized trials: an application of the non-parametric bootstrap. Stat Med 19:3219-3236

20. Crawshaw BP, Chien HL, Augestad KM, Delaney CP (2015) Effect of laparoscopic surgery on health care utilization and costs in patients who undergo colectomy. JAMA Surgery 150:410-415

21. Nygren J, Thacker J, Carli F, Fearon KC, Norderval S, Lobo DN, Ljungqvist O, Soop M, Ramirez J, Enhanced Recovery After Surgery Society fPC, European Society for Clinical N, Metabolism, International Association for Surgical M, Nutrition (2013) Guidelines for perioperative care in elective rectal/pelvic surgery: Enhanced Recovery After Surgery (ERAS((R))) Society recommendations. World J Surg 37:285-305

22. Kennedy RH, Francis A, Dutton S, Love S, Pearson S, Blazeby JM, Quirke P, Franks PJ, Kerr DJ (2012) EnROL: a multicentre randomised trial of conventional versus laparoscopic surgery for colorectal cancer within an enhanced recovery programme. BMC Cancer 12:1

23. Vlug MS, Wind J, Hollmann MW, Ubbink DT, Cense HA, Engel AF, Gerhards MF, van Wagensveld BA, van der Zaag ES, van Geloven AA, Sprangers MA, Cuesta MA, Bemelman WA, Group Ls (2011) Laparoscopy in combination with fast track multimodal management is the best perioperative strategy in patients undergoing colonic surgery: a randomized clinical trial (LAFA-study). Ann Surg 254:868-875 